\title{
A AMIZADE E A ÉTICA DA PSICANÁlise
}

FRIENDSHIP AND ETHICS OF PSYCHOANALYSIS

LA AMISTAD Y LA ÉTICA DEL PSICOANÁLISIS

Jô Gondar*

Resenha do livro: Oliveira, L. C. P. (2012). O sentido da amizade em Ferenczi: uma contribuição à clínica psicanalitica. Rio de Janeiro: Uapê. 230 p.

Muito se escreve, no campo analítico, a respeito do amor, e principalmente do amor de transferência. Pouco se escreve a respeito da amizade. Existem, na obra de Freud e de outros analistas, alguns poucos comentários sobre a constituição da amizade, mas sáo raros os que tratam dela no movimento da psicanálise, seja na relação transferencial ou entre pares. James Strachey, tradutor e editor das obras de Freud na língua inglesa, lista seis ocorrências do termo "amizade" nos textos freudianos, quase todas se referindo ao seu engendramento na sexualidade ou no retorno do erotismo nos laços de parceria. Freud faz apenas um comentário, em "Análise terminável interminável" (1937), sobre a possibilidade de uma relação amistosa ocorrer entre terapeuta e paciente, para além do vínculo transferencial. Não há qualquer menção a sua importância na própria transferência, na relação entre pares ou na constituição do corpus psicanalítico. É, de fato, surpreendente, se levamos em conta que a psicanálise, tanto no plano teórico quanto clínico e institucional, nasce sob o signo da amizade. Desde a elaboração da análise de Freud com Fliess, passando pelas relaçóes de aproximação e ruptura de Freud com Jung, Adler e Rank, a instauração do "comitê secreto" e até mesmo a instituição da IPA, é todo o movimento psicanalítico que percorre, em suas diversas facetas, o fio do amigo. Com Ferenczi, talvez este vínculo tenha sido mais forte e mais duradouro, a ponto de Freud afirmar que, por muitos anos, os textos de um e de outro poderiam, indistintamente, ser assinados por qualquer um dos dois SF, tanto o vienense Sigmund quanto o húngaro Sándor: "[Muitos temas evocados durante anos] ingressaram na literatura com o nome dele ou com o meu” (Granoff, 1961).

* Universidade Federal do Estado do Rio de Janeiro, Rio de Janeiro, RJ, Brasil. 
A despeito da confiança, respeito e mútua admiração que os liga, os dois SF possuem índoles e interesses distintos. Para Freud, trata-se de buscar reconhecimento científico e conquistar a adesão ao saber por ele construído. Para Ferenczi, trata-se de experimentar parcerias afetivas capazes de acolher e transformar o sofrimento de seus pacientes. Sem dúvida, é para o SF húngaro que a questão da amizade vai se mostrar fundamental. Em diversos momentos, é ela que dá o tom de sua pesquisa clínica, mesmo não sendo abordada de maneira sistemática. Não há uma teoria da amizade em Ferenczi, embora se trate de um tema capital em seu modo de pensar e de exercer a psicanálise.

O livro de Luiz Ricardo Prado de Oliveira, originalmente sua tese de doutorado no Instituto de Medicina Social da UERJ, sob a orientação de Francisco Ortega, realiza três funçóes fundamentais para o tratamento desse tema. A primeira é a de estabelecer, a partir da parceria intelectual e dos laços de amizade entre Freud e Ferenczi, os contornos e os matizes de uma teorização que já há algum tempo se fazia necessária em nosso meio. Qual é o sentido da amizade em Ferenczi? Luiz Ricardo nos apresenta a diversos deles. Desde a dependência e idealização do vínculo de Ferenczi com Freud, nos primeiros anos da psicanálise, até a proposta, já na década de 30 , de pensar a relação entre analista e analisando como um encontro entre duas crianças sem pai nem mãe, é a busca da parceria que move, sob matizes diferenciados, a construção e a experimentação do psicanalista húngaro. São inúmeras as ocasiôes em que utiliza o termo amizade, ou outro similar, em seus escritos, enfatizando como esse laço afetivo funciona como um combustível indispensável à análise. Mas Ferenczi vai além: boa parte dos conceitos que desenvolve e dos procedimentos técnicos que inventa são construídos a partir da defesa de uma "amizade tácita" na relação analítica: a ideia de um dialogo de inconscientes, a proposta de "sentir com", a denúncia de uma "hipocrisia professional”, a análise pelo jogo, a confissão dos próprios erros, a preocupação com a franqueza e a sinceridade, a ênfase numa atmosfera de confiança.

A segunda função importante do livro diz respeito à mudança que a relação transferencial experimenta na clínica contemporânea. O lugar do suposto saber, tão confortavelmente ocupado pelos analistas até então, não precisa hoje do término de um processo analítico para ser destituído. A destituição já se apresenta no início do tratamento - na verdade, porque esse lugar não chegou a ser instituído - com pacientes pouco afeitos ao endereçamento de questóes e à elaboraçáo psíquica, desprovidos de ideais e de instâncias simbólicas que poderiam lhes fornecer sustentaçấo subjetiva. Luiz Ricardo os chama de pacientes operatórios e destaca seu modo de funcionamento pragmático, ligado à concretude da existência. De fato, o analista só pode ocupar o lugar de representante da lei, o de 
enigma, e mesmo o de resto, na medida em que um Outro lugar dispóe e organiza as relaçóes, sejam elas familiares, sociais ou o próprio vínculo transferencial. A destituição contemporânea de um Outro simbólico impede que o analista se situe em qualquer lugar que tome esse Outro como referência, mesmo que seja o de resto de uma operação. Como seria possível, a partir disso, teorizar a relação transferencial? Na ausência de um Outro simbólico, o que poderia sustentá-la?

Luiz Ricardo nos mostra, com Ferenczi, que nem todos os laços transferenciais se erigem a partir da suposição de uma verticalidade hierárquica. De fato, as relações verticais derivam, em última instância, de uma simbólica familialista dos vínculos afetivos, já que o modelo tradicional de família implica sempre hierarquia e verticalidade entre pais e filhos. Mas é justamente dessa verticalidade que não dispomos mais em nossas novas configuraçóes de mundo. Disso dão testemunho sofrimentos como o pânico e as compulsóes, indicando a ausência ou a inoperância de um lugar terceiro regulador. Ora, o que faz Ferenczi senão trabalhar justamente nesse registro, senão denunciar o analista que pretende fazer uso - por narcisismo ou conforto - "do chapéu do nosso pai, de sua bengala e de seu ar de importância?” (Ferenczi, 1930/1992, p. 218). O universo clínico e conceitual ferencziano é um universo horizontal, e é por este motivo que sua lógica - distinta daquela sob a qual operou um Freud ou mesmo um Lacan - nos soa hoje tão atual. Nossos pacientes não acreditam mais em instâncias da verticalidade, sejam elas os pais, os representantes políticos ou os psicanalistas. Isso não significa que não possam mais existir relaçóes transferenciais; significa apenas que seu registro de funcionamento se modifica. É neste plano que Ferenczi joga: a linha horizontal é a linha do amigo. Para entrar em contato com a criança que existe no adulto, o analista conta com a criança que ele também é; para isso arrisca-se na mesma linha de seu paciente, partilhando sua vulnerabilidade na experiência clínica. $\mathrm{O}$ analista não se coloca apenas no lugar do pai, da mãe, ou do objeto enigmático causante do desejo. Para Ferenczi ele é sobretudo um parceiro que, desprovido de uma comunidade de origem sustentada numa autoridade central - o amigo não é um irmão -, estabelece com seu paciente uma relação atravessada pela precariedade e pela solidão trágica de todos nós.

Um terceiro ponto importante trazido no livro é o fato de sua discussão sobre a amizade não se reduzir à esfera da clínica psicanalítica, abarcando também o campo ético e político. É oportuno que, num momento de incremento do individualismo, a psicanálise possa fornecer sua contribuição crítica aos modos de vida contemporâneos. Essa contribuição não precisa - e não deve - dar-se apenas num sentido negativo, como um inventário dos valores que se encontram hoje em derrocada, pode ser feita também num sentido afirmativo, ao apontar as 
estratégias que os sujeitos individuais e coletivos dispóem para estabelecer novas modalidades de laço social. Aqui a amizade aparece em sua "essência revolucionária”, como propóe Luiz Ricardo. É de suma importância, adverte ele, que os psicanalistas procedam a uma reflexão sobre uma disposição afetiva baseada na amizade, cooperação e solidariedade, já que ela é, atualmente, um dos grandes instrumentos de combate aos efeitos traumáticos do individualismo em todos os níveis. Isso mostra que os dispositivos técnicos da psicanálise são também dispositivos políticos, e que o trabalho da clínica náo se desvincula de uma luta mais ampla pelo direito ao presente, com todos os problemas e novidades que ele nos traz.

Os três planos em que Luiz Ricardo trata o tema da amizade - conceitual, técnico e ético-político - se interpenetram neste livro. E ganham maior densidade com a colaboração de dois filósofos - Derrida e Foucault. Com Derrida aprendemos que somente uma "cegueira falogocêntrica" é capaz de identificar o amigo às figuras do próximo e do irmão. Essa cegueira exclui da amizade as mulheres, os sentimentos de ódio pelo parceiro e a possibilidade de se vincular ao diferente, ao estrangeiro, ao distante. O modelo tradicional de amizade é homossexual, narcísico e familialista: supóe um pai todo-poderoso que garante a lei transcendente, os laços fraternos e as insígnias do eu. Derrida propóe que a amizade se afaste de uma concepção familialista e se estabeleça sob outros parâmetros sociais e políticos, a partir dos quais os habitantes da polis se tornem capazes de acolher a diferença e suportar uma tensão irredutível.

Com Foucault aprendemos que a amizade pode promover a autonomia - e não a submissão - dos que nela estão envolvidos, porém sob uma forma que nada tem de individualista. A noção foucaultiana de "cuidado de si" implica uma autoconstituição ética de si através da relação com o outro; trata-se de, nessa relação, inventar modos alternativos de viver que estabeleçam uma deriva às formas de poder vigentes num determinado campo social. Desse modo, a amizade pode participar de uma resistência ao poder pela criação de uma "estética da existência”. Cabe observar que tanto Derrida quanto Foucault vão ao encontro do que Ferenczi teoriza e experimenta na clínica, fornecendo uma sustentação teórica para aquilo que ele realizou algumas vezes por índole ou puro instinto, mas sempre movido pela ideia de que a transformação do sofrimento passa pela conquista da autonomia, pelo risco compartilhado e pela confiança entre parceiros ligados pela mesma precariedade. Uma amizade feita entre órfâos, constituindo uma espécie de comunidade dos sem comunidade.

Em suma, na companhia de Freud, Foucault e Derrida, a pesquisa de Luiz Ricardo Prado desenvolve, em torno de Ferenczi, um tema bastante oportuno face aos modos de subjetivação contemporâneos, abrindo outras possibili- 
dades de trabalho no contexto clínico e de resistência crítica no espaço social e político. Este livro nos convida a não separar os dois campos e, nesse sentido, a pensar a prática psicanalítica também como uma prática da polis. Como afirma Luiz Ricardo, se o laço de amizade em Ferenczi funciona como uma ética da clínica, as relaçôes de parceria, alternadamente simétricas e assimétricas, implicam a possibilidade de este trabalho ser processado a partir de uma nova política da clínica psicanalítica.

\section{Referências}

Granoff, W. (1961). Ferenczi: faux problème ou vrai malentendu? La Psychanalyse, 6, 255-282. Ferenczi, S. (1992). O tratamento psicanalítico do caráter. In S. Ferenczi. Obras completas: Psicanálise IV (pp. 215-221). São Paulo: Martins Fontes. (Trabalho original publicado em 1930).

Recebido em 30 de agosto de 2013 Aceito para publicação em 10 de novembro de 2013 